омбинированная терапия диссеминированной формы кольцевиАной гранулемы

\author{
Карамова А. Э., Знаменская Л. Ф., Свищенко С. И., Жилова М. Б., Нефедова М. А., Пугнер А. С. *
}

ФГБУ «Государственный научный центр дерматовенерологии и косметологии» Минздрава России

107076, Россия, г. Москва, ул. Короленко, д. 3, стр. 6

Цель. Представить результаты лечения диссеминированной формы кольцевидной гранулемы с применением дальней длинноволновой ультрафиолетовой терапии и низкоинтенсивной лазерной терапии.

Материал и методы. 2 пациенткам в возрасте 50 и 53 лет, обратившимся с жалобами на распространенные высыпания на коже туловища, верхних и нижних конечностей и гистологически верифрицированным диагнозом, проведено комбинированное лечение с применением дальней длинноволновой ультрафиолетовой терапии и низкоинтенсивной лазерной терапии инфракрасного спектра. Проведено 16 процедур общей дальней длинноволновой ультрафриолетовой терапии и 10 процедур низкоинтенсивной лазерной терапии контактно на очаги поражения. Учитывая разнонаправленность механизмов действия методов фототерапии и лазеротерапии, процедуры проводились в разные дни либо с многочасовым интервалом.

Результаты. При использовании метода дальней длинноволновой ультрафиолетовой терапии в комбинации с лазерной терапией отмечено существенное улучшение к 21-му дню терапии. Побочных эфрфектов в процессе лечения не отмечалось, переносимость процедур была хорошая.

Заключение. Комбинированное применение дальней длинноволновой ультрафиолетовой терапии и низкоинтенсивной лазерной терапии инфракрасного спектра является эфффективным при лечении диссеминированной формы кольцевидной гранулемы.

Ключевые слова: кольцевидная гранулема, пУВА-терапия, УФА-1 терапия, низкоинтенсивное лазерное излучение.

Конфрликт интересов: авторы заявляют об отсутствии потенциального конфрликта интересов, требующего раскрытия в данной статье.

Для цитирования: Карамова А. Э., Знаменская Л.Ф., Свищенко С.И., Жилова М.Б., Нефедова М. А., Пугнер А. С. Комбинированная терапия диссеминированной фрормы кольцевидной гранулемы. Вестник дерматологии и венерологии. 2020; 96 (1): 34-44. https://doi.org/10.25208/vdv549-2020-96-1-34-44 


\title{
Combination treatment of disseminated granuloma annulare
}

\author{
Arfenya E. Karamova, Lyudmila F. Znamenskaya, Svetlana I. Svishchenko, Mar'yana B. Zhilova, Maria A. Nefedova, Anna S. Pugner*
}

State Research Center of Dermatovenereology and Cosmetology, Ministry of Health of the Russian Federation

Korolenko str., 3, bldg 6, Moscow, 107076, Russian Federation

Purpose. To present the results of the treatment of disseminated form of granuloma annulare with remote long-wave ultraviolet therapy and low level laser therapy.

Material and methods. Two female patients at the age of 50 and 53 years with complaints of generalised eruptions on the skin of the trunk, upper and lower limbs and a histologically confirmed diagnosis were treated using a combination of remote long-wave ultraviolet therapy and low level laser therapy of infrared spectrum. 16 sessions of remote long-wave ultraviolet therapy and 10 sessions of low level laser therapy were conducted directly on the lesions. Considering the multidirectionality of the mechanisms of action of phototherapy and laser therapy, the procedures were carried out on different days or with many hours long intervals.

Results. Combined use of the remote long-wave ultraviolet therapy and laser therapy led to a significant improvement by the 21 st day of the treatment. No side effects were noticed during the treatment, tolerance of the sessions was good.

Conclusion. Combined use of the remote long-wave ultraviolet therapy and low level laser therapy of infrared spectrum is effective in treatment of disseminated form of granuloma annulare.

Keywords: granuloma annulare, PUVA-therapy, UVA1-phototherapy, low-level laser radiation.

Conflict of interest: the authors state that there is no potential conflict of interest requiring disclosure in this article.

For citation: Arfenya E. Karamova, Lyudmila F. Znamenskaya, Svetlana I. Svishchenko, Mar'yana B. Zhilova, Maria A. Nefedova, Anna S. Pugner. Combination treatment of disseminated granuloma annulare. Vestnik Dermatologii i Venerologii. 2020; 96 (1): 34-44. https://doi.org/10.25208/vdv549-2020-96-1-34-44 
Кольцевидная гранулема - доброкачественное неинфекционное воспалительное заболевание кожи, характеризующееся появлением кольцевидно расположенных папул и развитием гранулематозного воспаления [1]. Впервые дерматоз был описан в 1895 г. доктором К. Фоксом в виде «кратера» и «овального кольца» на коже пальца 11-летней девочки. В 1902 г. заболевание получило название «кольцевидная гранулема» [2].

Кольцевидная гранулема считается достаточно редким заболеванием, встречается в любом возрасте, однако чаще развивается у детей и у взрослых молодого возраста, имеет благоприятный прогноз. Установлено, что женщины болеют в 2-2,5 раза чаще, чем мужчины [3-5]. Этиология заболевания остается неизвестной. В современной литературе описаны случаи кольцевидной гранулемы, ассоциированные с заболеваниями щитовидной железы, злокачественными опухолями, сахарным диабетом, нарушениями липидного обмена, вирусными инфекциями (опоясывающий герпес, вирус Эпштейна - Барр, вирусные гепатиты В и С), туберкулезом, саркоидозом [6-21]. Имеются единичные данные о развитии кольцевидной гранулемы после татуажа, укусов насекомых, вакцинации, мезотерапии, приема лекарственных препаратов (аллопуринол, топирамид, ингибиторы фактора некроза опухоли- $\alpha$ ) [22-28]. Выявлена ассоциация кольцевидной гранулемы с антигенами системы HLA, в частности, у больных с локализованной фрормой часто определяют HLA-B8, с диссеминированной формой — HLA-A29 и HLA-BW35 [29].

В патогенезе кольцевидной гранулемы основное место отводят реакциям гиперчувствительности замедленного типа, а также экспрессии фрактора некроза опухоли- $\alpha$, интерлейкина-2, интерлейкина-18 [30-32]. По мнению ряда авторов, в патогенезе дерматоза существенную роль играет развитие микроангиопатии [5]. Однако в настоящее время не получено данных, что же является первичным: повреждение соединительной ткани с развитием микроангиопатии либо васкулит с последующим формированием гранулем [33].

Описано несколько клинических форм кольцевидной гранулемы. Локализованная форма встречается в $75 \%$ случаев, наиболее часто у детей высыпания локализуются преимущественно на коже тыла кистей и стоп. Спонтанный регресс наблюдается в течение 2 лет в 50\% случаев [34]. Подкожная фрорма встречается в основном у детей до 5 лет, характеризуется плотными узлами на коже нижних конечностей, ягодичной области, волосистой части головы, которые могут разрешаться самостоятельно [35]. Перфорирующая форма встречается довольно редко, преимущественно на коже кистей, проявляется мелкими поверхностными папулами с западением в центре или корочками, возможно выделение желатиноподобного содержимого и образование рубцов [36]. Дугообразная дермальная форма представлена крупными очагами, образованными гиперпигментированными и эритематозными пятнами, папулы встречаются редко [37].

Диссеминированная форма встречается в 15\% случаев у пациентов старше 40 лет. Высыпания распространенные, симметричные, в большинстве случаев самостоятельно не регрессируют, а эффрективность системных и наружных методов терапии дискутируется [1]. Различают 4 гистологических подтипа коль- цевидной гранулемы: палисадный, интерстициальный («непалисадный»), саркоидный и смешанный [38]. Палисадный подтип представлен фокусом дезорганизации соединительной ткани, вокруг которого отмечается лимфоцитарный инфильтрат и палисадно расположенные гистиоциты, формирующие гранулемы. При интерстициальном подтипе гистиоциты расположены между фррагментированными коллагеновыми волокнами. При саркоидном подтипе обнаруживаются эпителиоидные гистиоциты, что может имитировать гранулемы саркоидного типа. Однако обилие муцина, обнаруживающегося в 94\% случаев, является отличительной чертой в дифференциальном диагнозе с другими неинфрекционными гранулематозными заболеваниями, в частности, саркоидозом и липоидным некробиозом [39-41].

Известно, что все методы фрототерапии оказывают иммуносупрессивное, антипролиферативное и противовоспалительное действие, что патогенетически обосновывает их применение при диссеминированных фрормах заболевания [42, 43]. Особенностью воздействия дальнего длинноволнового диапазона 350-400 нм (УФА-1) помимо вышеуказанных механизмов является модуляция активности матриксных мелаллопротеиназ, участвующих в расщеплении дезорганизованных коллагеновых волокон в дерме [44, 45]. Имеются данные, что низкоинтенсивное лазерное излучение способствует улучшению микроциркуляции в дерме и разрешению проявлений микроангиопатии [46].

С целью повышения эффрективности терапии предложена комбинация двух фризических фракторов, влияющих на различные патогенетические механизмы при кольцевидной гранулеме.

\section{Приводим собственные клинические наблюдения}

Клинический случай №1.

Пациентка Т., 53 года, поступила в отделение клинической дерматологии ФГБУ «ГНЦДК» Минздрава России с жалобами на высыпания на коже туловища, верхних и нижних конечностей, сопровождающиеся незначительным зудом.

Считает себя больной с 2016 г., когда впервые после психоэмоционального перенапряжения отметила появление розового пятна на коже тыльной поверхности правой кисти, отмечался незначительный зуд. За медицинской помощью не обращалась, самостоятельно использовала мази левомеколь, ацикловир без эффректа. В течение года высыпания распространились на кожу туловища, верхних и нижних конечностей. В 2017 г. при обращении к врачу-дерматологу по месту жительства поставлен диагноз “Дерматит», назначен преднизолон в дозе 10 мг перорально в течение 2 дней, далее по 5 мг в сутки, через день в течение 8 дней без эффректа. В апреле 2019 г. при повторном обращении к врачу-дерматологу по месту жительства установлен диагноз кольцевидной эритемы Дарье, назначены витаминотерапия, антигистаминные препараты, топические глюкокортикостероиды без эффекта. В сентябре 2019 г. обратилась на консультацию к врачу-дерматологу КДЦ ФГБУ «ГНЦДК» Минздрава России, где поставлен диагноз кольцевидной гранулемы, диссеминированной формы? С целью уточнения диагноза проведена диагностическая биопсия кожи, по заключению которой: «эпидермис утолщен с умеренным гиперкератозом. В средних и глубоких отделах дер- 


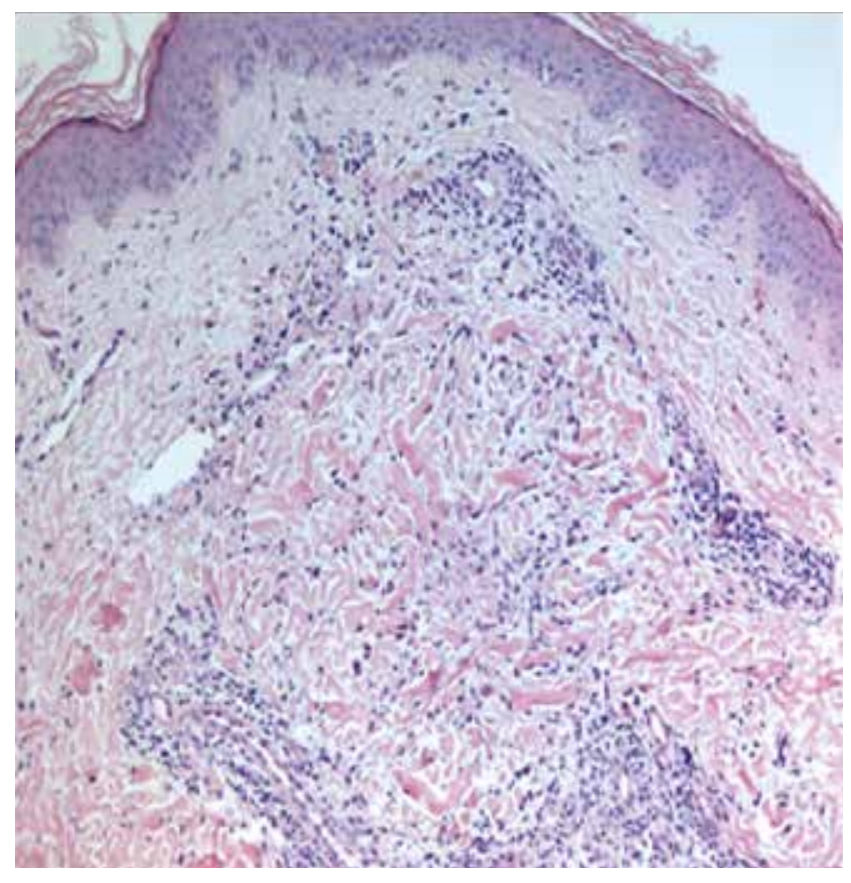

a

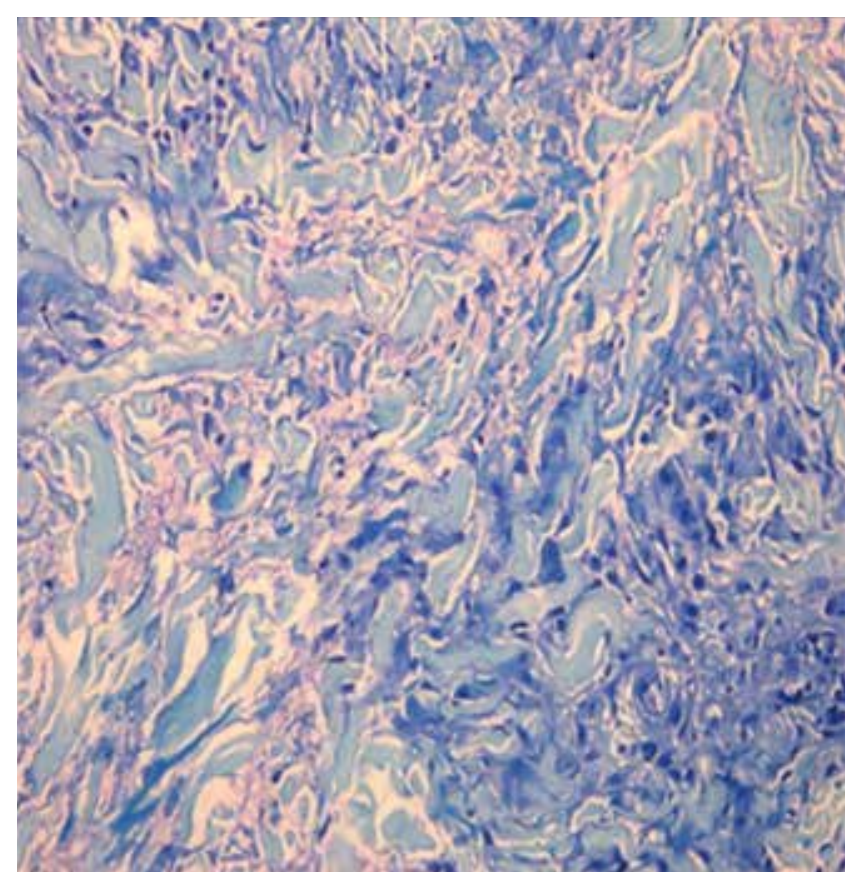

$\sigma$

\footnotetext{
Рис. 1. Кольцевидная гранулема. Гистологическое исследование биоптата кожи. Эпидермис утолщен с умеренным гиперкератозом. В средних и глубоких отделах дермы мелкие фокусы дезорганизации соединительной ткани, окруженные лимфогистиоцитарным инфильтратом с палисадным расположением гистиоцитов (а - окраска гематоксилином и эозином, × 100). Слабая метахромазия, свидетельствующая о наличии муцина (б - окраска толуидиновым синим, × 400)

Fig. 1. Granuloma annulare. Histological examination of skin biopsy. The epidermis is thickened with moderate hyperkeratosis. There are small foci of connective tissue disorganization surrounded by lymphohistiocytic infiltrate with a palisade arrangement of histiocytes in the middle and deep departments of dermis. (a - hematoxylin and eosin stain, $\times 100)$. Weak metachromasia, showing at the presence of mucin $(6$ — toluidine blue stain, $\times 400)$
}

мы мелкие фрокусы дезорганизации соединительной ткани, окруженные лимфогистиоцитарным инфильтратом с палисадным расположением гистиоцитов, при окраске толуидиновым синим отмечается слабая метахромазия. Заключение: выявленные изменения соответствуют клиническому диагнозу кольцевидной гранулемы» (рис. 1).

Сопутствующие заболевания: витилиго, пролапс внутренних половых органов 1-2-й степени, узловой зоб 1-й степени, гиперметропия слабой степени обоих глаз. Локальный статус при поступлении: кожный патологический процесс носил распространенный характер, высыпания на коже туловища, верхних и нижних конечностей представлены множественными симметричными очагами размером от 2 до $10 \mathrm{cm,} \mathrm{в} \mathrm{виде}$ гладких, блестящих узелков, расположенных кольцевидно, преимущественно неправильной фрормы, цвет которых варьировал от ярко-розового с синюшным и/или буроватым оттенком до бледно-розового. На коже нижних конечностей множественные депигментированные пятна диаметром от 1 см до 4 см молочно-белого цвета с четкими границами. Свечение очагов депигментации под лампой Вуда ярко-белого цвета (рис. 2).

Клинический анализ крови, общий анализ мочи в пределах референсных значений, биохимический анализ крови - холестерин 6,72 ммоль/л, остальные показатели в пределах референсных значений.

Согласно федеральным клиническим рекомендациям основным методом ффизиотерапевтического лечения диссеминированной формы кольцевидной гранулемы является ПУВА-терапия, однако, учитывая сопутствующую патологию - витилиго, целесообразным явилось использование метода дальней длинноволновой ультрафиолетовой терапии, не вызывающего фотодерматита, ввиду отсутствия эритемогенного диапазона в спектре и достижения терапевтических доз излучения.

Консультирована врачами-специалистами: терапевтом, эндокринологом, гинекологом; противопоказаний к проведению общей УФ-терапии не выявлено.

Больной назначен курс общей УФА-1 терапии низкими дозами с режимом 5 раз в неделю в комбинации с курсом низкоинтенсивного лазерного излучения инфрракрасного спектра 890 нм с режимом 5 раз в неделю контактно на очаги поражения. Начальная доза УФА-1 облучения составила 1,0 Дж/см², максимальная - 10,0 Дж/см², суммарная - 59 Дж/см². Режим лазерного излучения непрерывный, мощность 80 Вт, длительность импульса 100 нс, частота 150-80 Гц, контактно, по 1-2 минуты на поле, всего 10 полей. Наружно использовалась мазь с бетаметазоном на высыпания с режимом 1 раз в сутки в течение 21 дня.

Всего проведено 16 процедур общей УФА-1 терапии и 10 процедур локального низкоинтенсивного лазерного излучения инфракрасного спектра. В результате проведенной терапии отмечалось уменьшение интенсивности эритемы высыпаний, регресс части элементов, уплощение папулезных элементов. В процессе проводимой терапии побочных эфффектов отмечено не было, процедуры больная переносила хорошо. Курс лечения завершен с улучшением. 


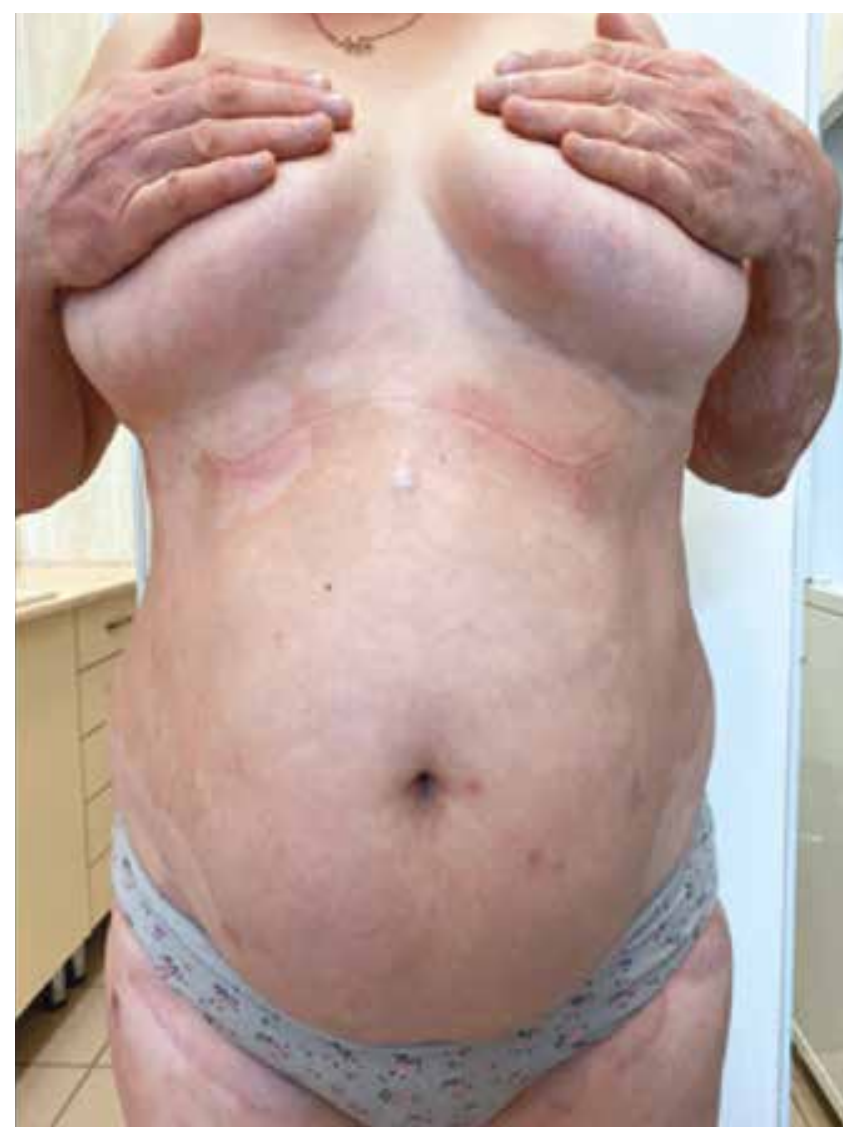

a

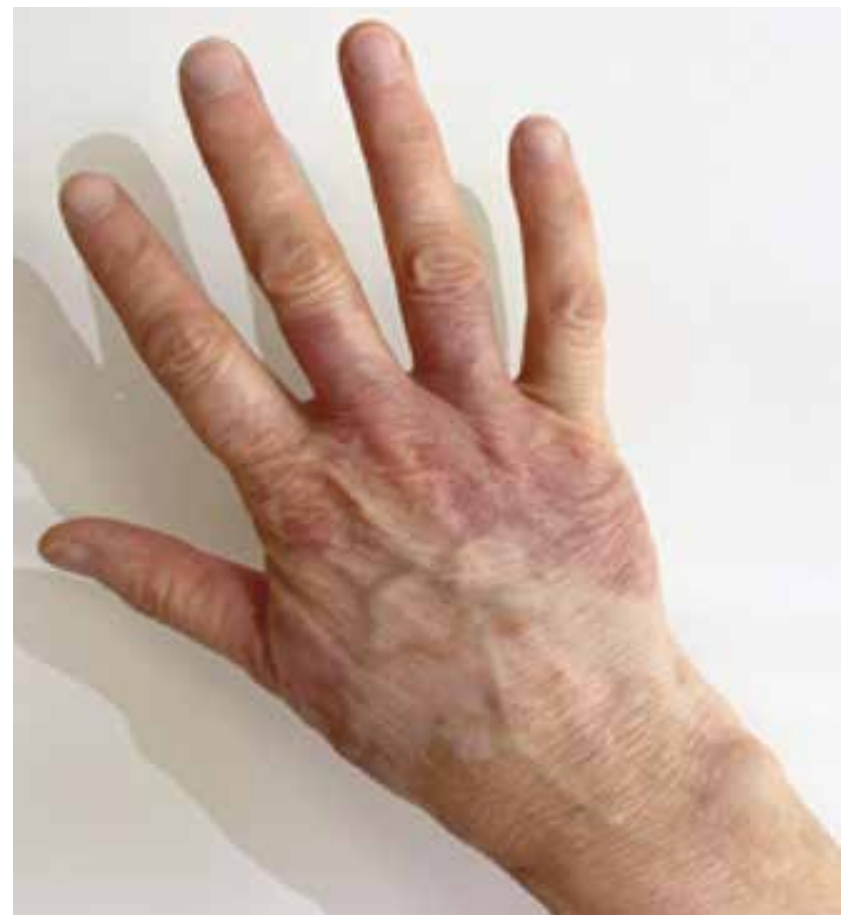

$B$

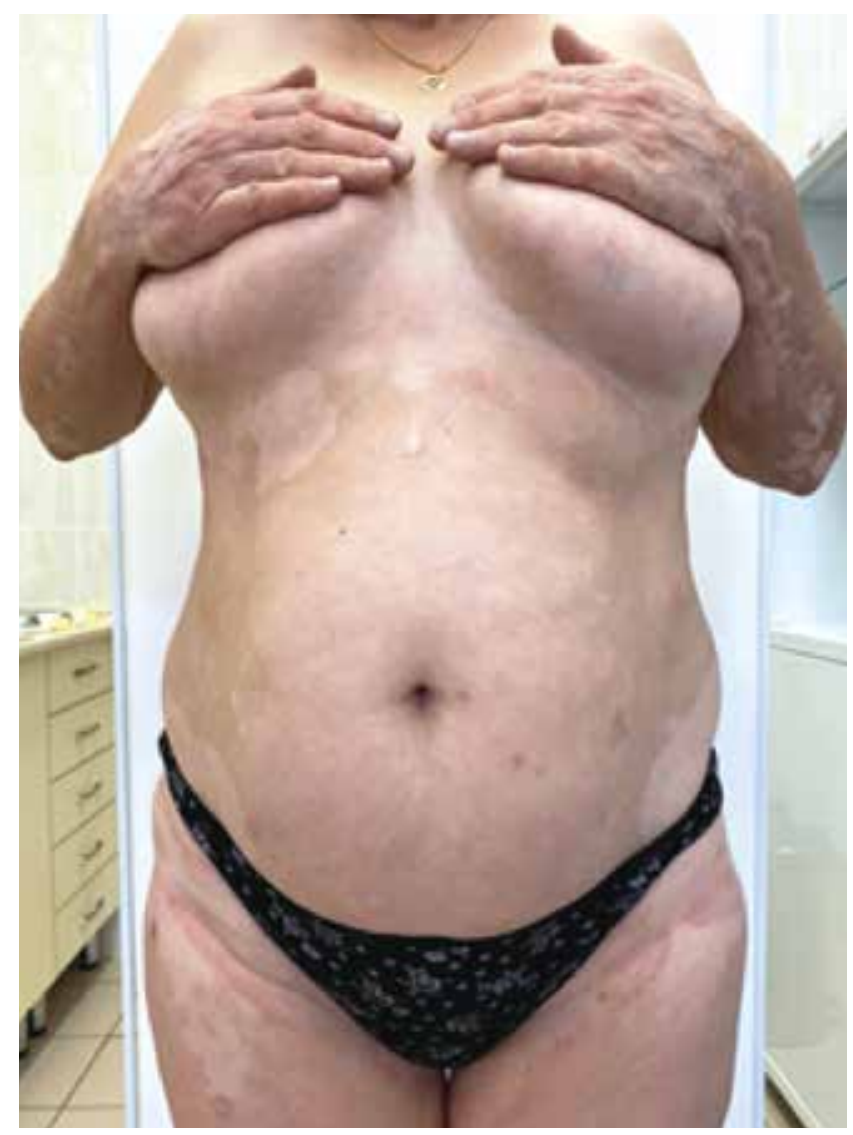

$\sigma$

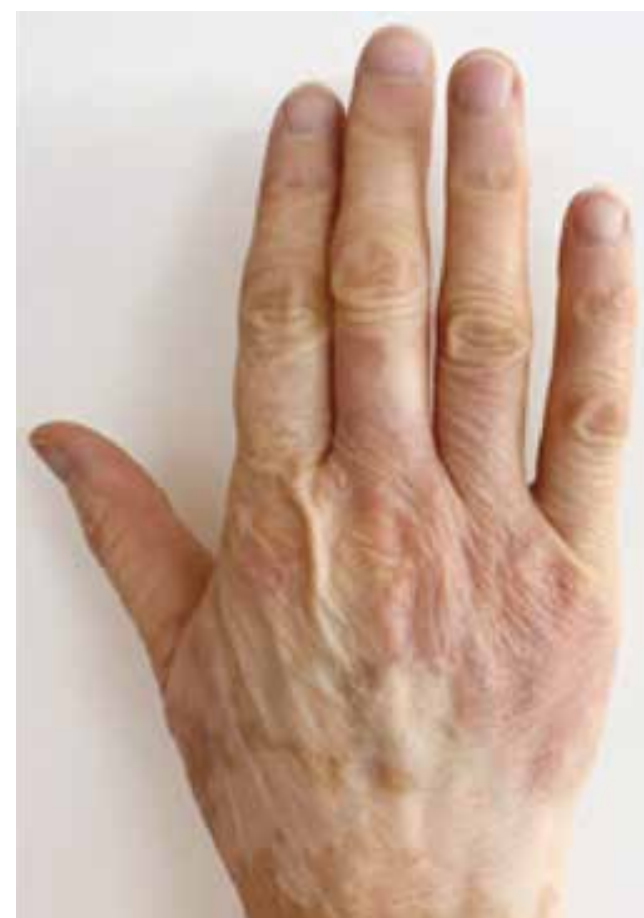

$\Gamma$

Рис. 2. Пятнистые кольцевидные очаги неправильной округлой и овальной фрормы, с периферическим венчиком розовато-синюшного цвета, кольцевидные очаги, сформированные блестящими, гладкими, уплощенными узелками бледно-розового цвета (а, В, Д, Ж - до лечения); уменьшение интенсивности окраски очагов поражения, уплощение узелковых элементов (б, г, е, з - после лечения)

Fig. 2. Spotted annular foci of irregular round and oval shape, with a peripheral corolla of a rose-cyanotic color, annular foci, formed by shiny, smooth, flattened nodules of pale

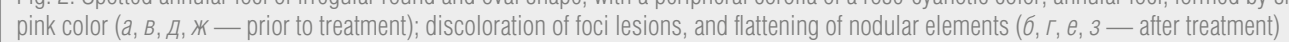




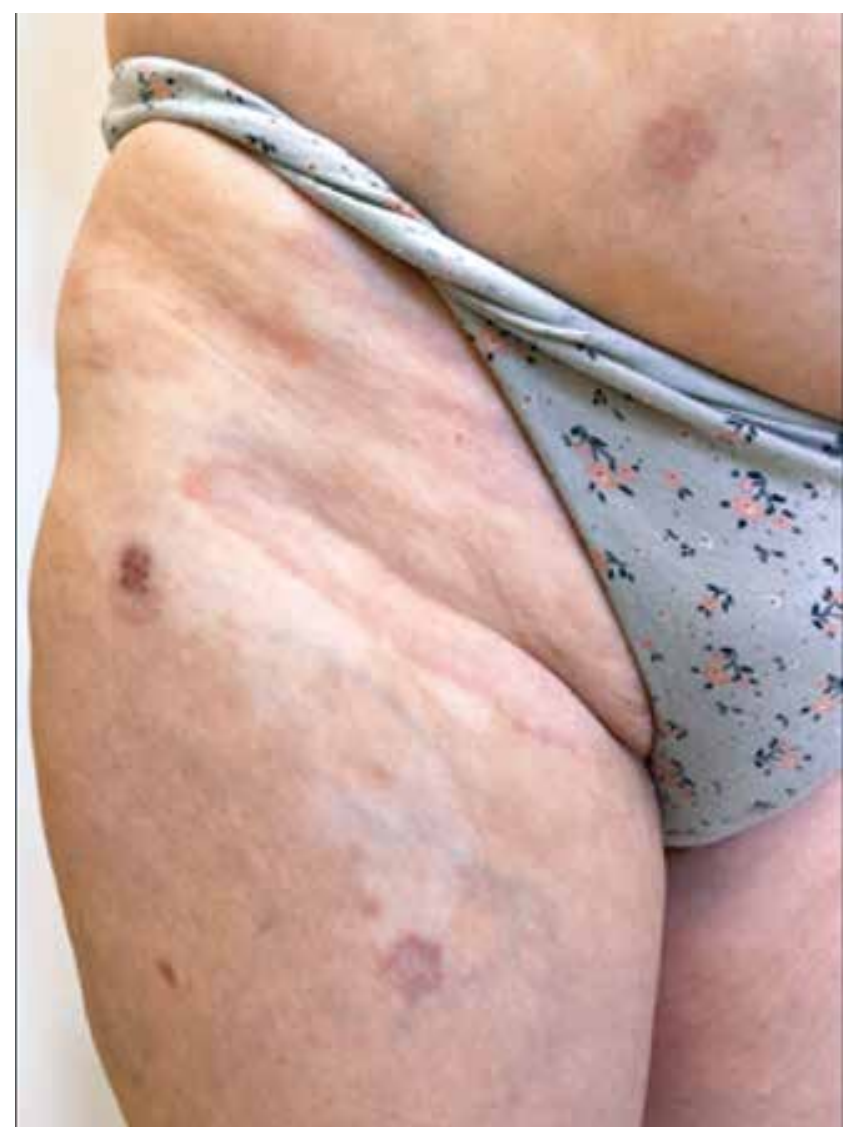

д

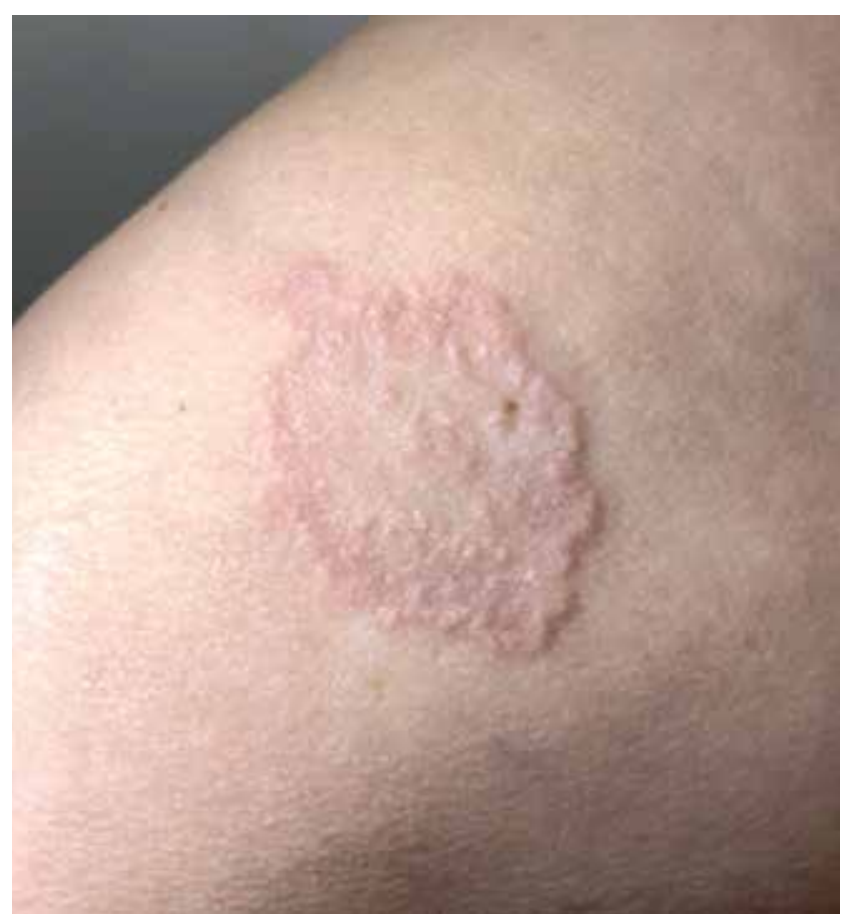

ж
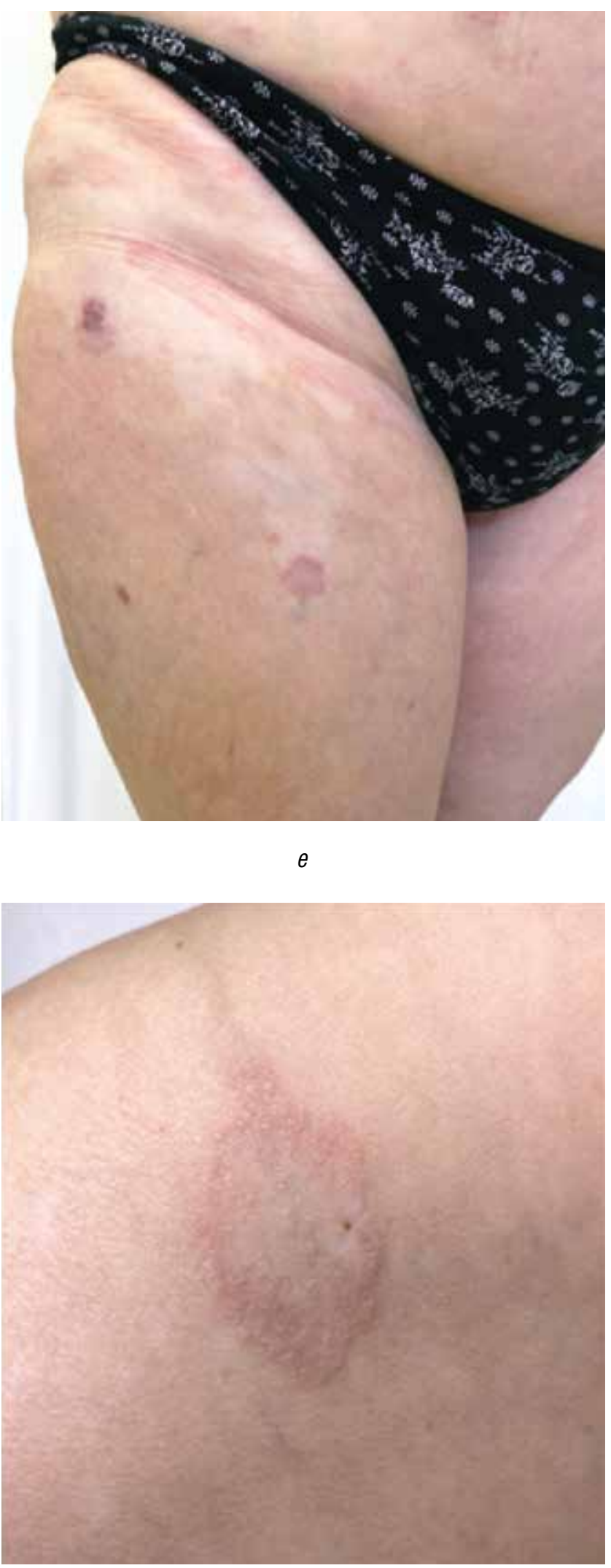

3 


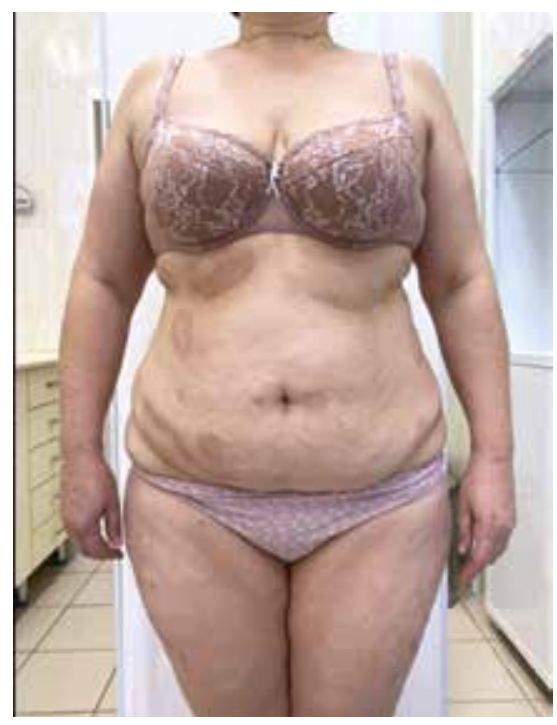

a

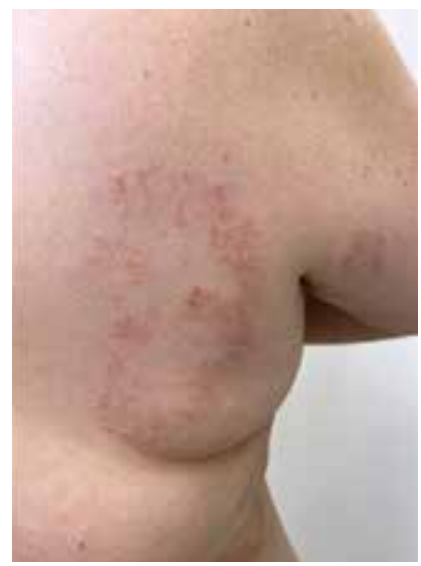

$\Gamma$

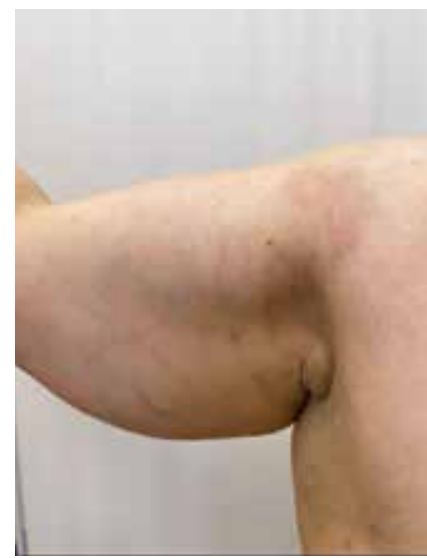

3

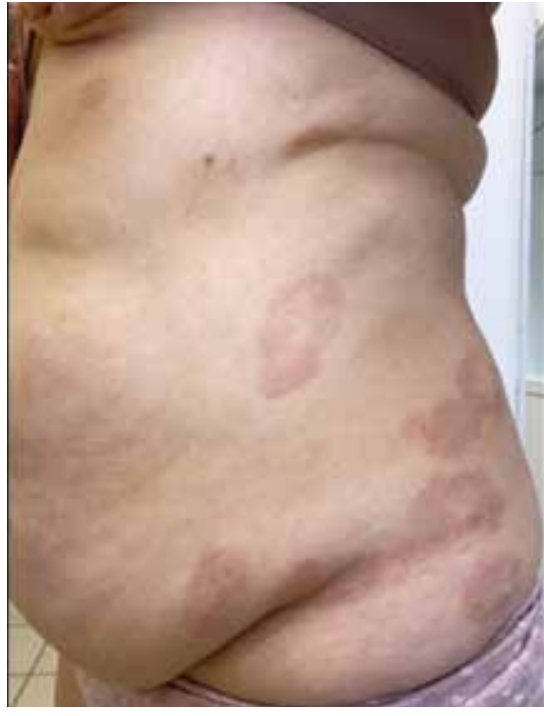

$\sigma$

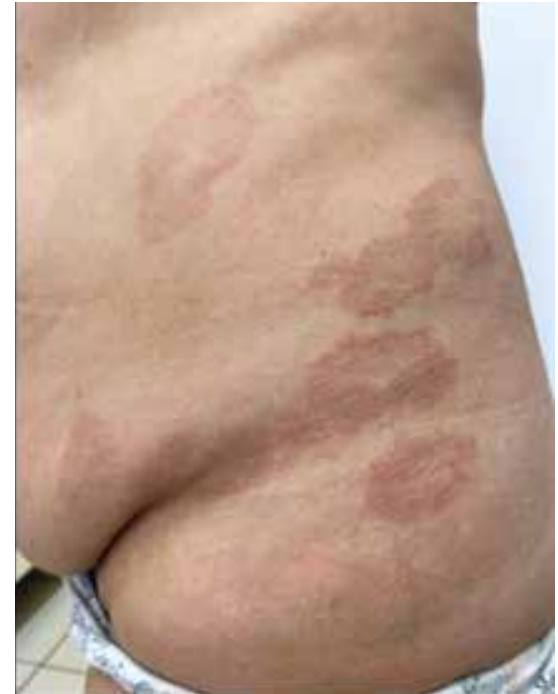

B

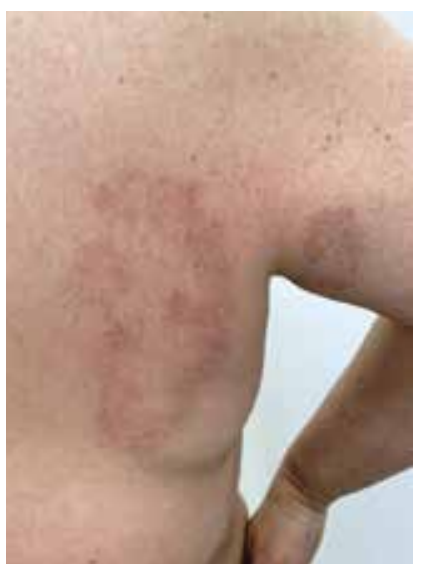

Д

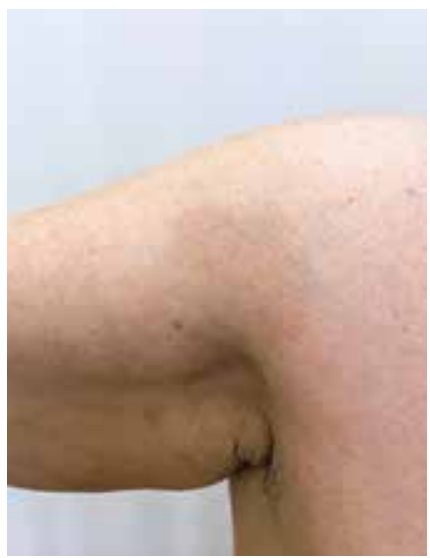

n

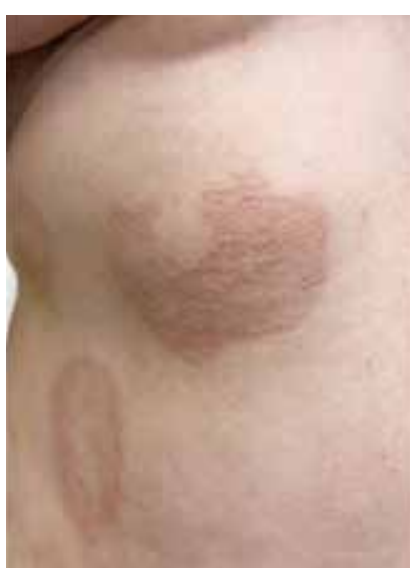

$e$

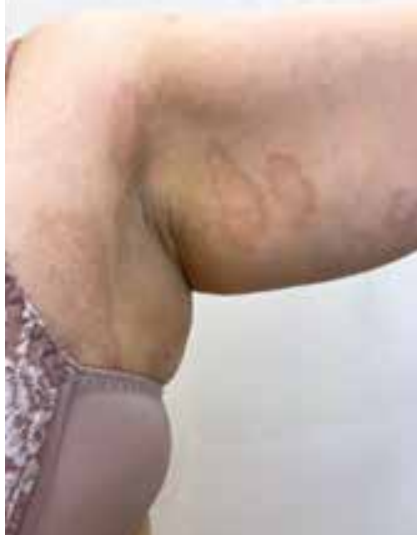

K

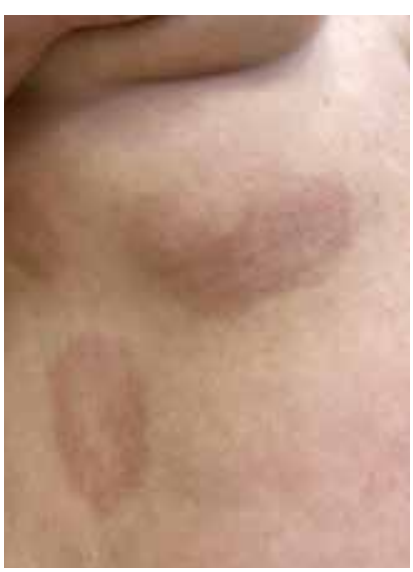

K

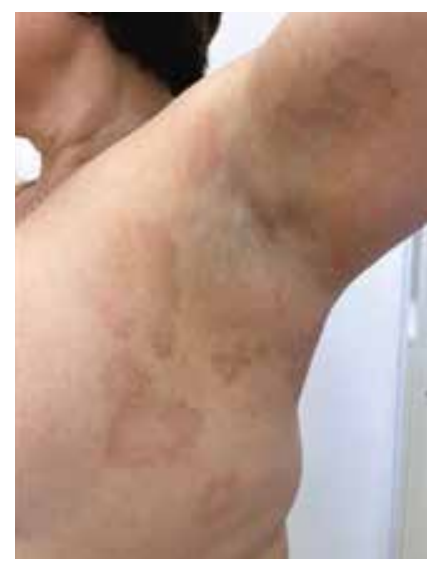

$ת$

\footnotetext{
Рис. 3. Пятна кольцевидной формы с периферическим венчиком застойного розового цвета, узелки розового цвета на поверхности элементов (а, б, г, е , 3, К - до лечения); уменьшение интенсивности эритемы высыпаний, регресс узелковых элементов с формированием пятен розового цвета, очаги гиперпигментации на коже подмышечных областей, наружных поверхностях плеч (в, Д, Ж, и, л- после лечения)

Fig. 3. Spots are ring-shaped with a peripheral rim of stagnant pink color, pink nodules on the surface of the elements ( $a, \sigma, \Gamma, e, 3, K$ - until treatment); decrease in the intensity erythema's rashes, regression of nodular elements with the formation of pink spots, foci of hyperpigmentation on the skin axillary areas, outer surfaces of the shoulders ( $B, Д, ж, и, л-$ after treatment)
} 
Клинический случай №2 2 .

Пациентка С., 50 лет, поступила в отделение клинической дерматологии ФГБУ «ГНЦДК» Минздрава России с жалобами на высыпания на коже туловища, верхних и нижних конечностей, сопровождающиеся незначительным зудом.

Считает себя больной с 2016 г., когда впервые отметила появление на коже передней брюшной стенки высыпаний, сопровождающихся незначительным зудом. При обращении к врачу-дерматологу по месту жительства поставлен диагноз атопического дерматита, проведено лечение (гипосенсибилизирующая терапия, антигистаминные и наружные препараты) без эффректа. В течение нескольких месяцев пациентка отметила возникновение новых высыпаний на коже верхних и нижних конечностей. При повторном обращении к врачу-дерматологу по месту жительства установлен диагноз кольцевидной эритемы. Назначена наружная терапия мазью с бетаметазоном 1 раз в сутки 10 дней, без эфректа. В октябре 2019 г. обратилась на консультацию к врачу-дерматологу в КДЦ ФГБУ «ГНЦДК» Минздрава России, поставлен диагноз кольцевидной гранулемы, диссеминированной фрормы, проведена диагностическая биопсия с последующим гистологическим исследованием. Заключение: «эпидермис обычной толщины, с незначительным акантозом, гребни сглажены, с незначительным ортокератозом. В сетчатой дерме - множественные фокусы дезорганизации соединительной ткани, окруженные лимфогистиоцитарным инфильтратом с участками палисадного расположения гистиоцитов. Периваскулярно густые муфртообразные лимфоцитарные инфильтраты. При окраске толуидиновым синим в фокусах дезорганизации коллагена отмечаются небольшие фокусы отчетливой метахромазии. В окружающей дерме умеренный фиброз. Заключение: выявленные изменения соответствуют клиническому диагнозу кольцевидной гранулемы».

На основании клинической картины заболевания, результатов гистологического исследования установлен диагноз кольцевидной гранулемы, диссеминированной формы. В связи с распространенностью кожного патологического процесса, отсутствием эффекта от проводимой терапии по месту жительства больная госпитализирована в стационар.

Сопутствующие заболевания: миопия слабой степени, сложный миопический астигматизм слабой степени правого глаза, смешанный астигматизм средней степени левого глаза, пресбиопия, начальная возрастная катаракта, желчнокаменная болезнь вне обострения, коллоидный узел щитовидной железы.

В клиническом анализе крови, биохимическом анализе крови, общем анализе мочи показатели в пределах референсных значений.

Локальный статус: кожный патологический процесс носил распространенный характер, локализовался на коже туловища, верхних и нижних конечностей, представлен воспалительными пятнами кольцевидной формы диаметром от 2 до 15 см, красновато-синюшного цвета с разрешением в центре, по периферии имелись плотные, гладкие полушаровидные узелки (рис. 3).

Учитывая наличие в анамнезе у больной катаракты, проведение ПУВА-терапии с пероральным приемом фотосенсибилизатора противопоказано. Консультиро- вана врачами-специалистами: терапевтом, эндокринологом, гинекологом; противопоказаний к проведению общей УФ-терапии не выявлено.

С учетом сопутствующей патологии была назначена комбинированная терапия с применением общей УФА-1 фототерапии низкими дозами с режимом 5 раз в неделю с экранированием глаз, области шеи и половых органов в сочетании с курсом локального низкоинтенсивного лазерного инфракрасного спектра 890 нм на очаги поражения с режимом 5 раз в неделю. Начальная доза общего УФА-1 облучения составила

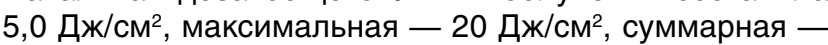
252 Дж/см². Режим лазерного излучения непрерывный, мощность 80 Вт, длительность импульса 100 нс, частота 80-150 Гц, контактно, по 2 минуты на поле, всего 10 полей. Наружно использовалась мазь с бетаметазоном на высыпания с режимом 1 раз в сутки в течение 21 дня.

Проведено 16 процедур общей УФА-1 фрототерапии и 10 процедур низкоинтенсивного лазерного излучения инфракрасного спектра на очаги поражения. На фоне проводимой терапии отмечалось уменьшение интенсивности окраски высыпаний, регресс папулезных элементов, формирование вторичной гиперпигментации.

В процессе проводимой терапии побочных эффектов отмечено не было, процедуры пациентка переносила хорошо, выписана со значительным улучшением.

\section{Обсуждение}

Лечение диссеминированной формы кольцевидной гранулемы представляет собой достаточно сложную задачу. Основной метод лечения локализованной фрормы кольцевидной гранулемы - использование глюкокортикостероидных мазей высокой степени активности. Однако, учитывая, что частота встречаемости распространенных форм заболевания составляет 15\% [47], проблема выбора метода терапии представляется весьма актуальной. В 2017 г. Nambiar K. G. и соавторами был описан клинический случай успешного лечения диссеминированной кольцевидной гранулемы препаратом пентоксифиллин перорально в дозе 400 мг 3 раза в сутки. Улучшение наблюдалось на 3-м месяце терапии, в течение 6 месяцев рецидивов не отмечалось [48]. В 2018 г. Chandan N. представил клиническое наблюдение успешного лечения двух пациентов амоксициллином и комбинацией доксициклина и пентоксифиллина, что послужило основанием предположить наличие бактериального компонента в патогенезе кольцевидной гранулемы [49]. В литературе имеются отдельные публикации об эффективности применения фотодинамической терапии. В среднем проводилось 5 сеансов с интервалом 2-4 недели, положительный эффект наблюдался с 4-й процедуры. Общая эффрективность лечения составила около $60 \%$ $[50,51]$. В 2019 г. Chen A. проведен анализ эффрективности генно-инженерных биологических препаратов у 34 пациентов с неинфекционными гранулематозными заболеваниями, из них у 27 была диагностирована кольцевидная гранулема. Использовались препараты инсрликсимаб, адалимумаб, устекинумаб и этанерцепт. Уже на 10-й неделе терапии у $80 \%$ больных, получавших терапию ингибиторами фактора некроза опухоли- $\alpha$, наблюдался положительный ответ, тогда 
как только у одного из пяти пациентов был отмечен ответ на этанерцепт [52]. Описаны единичные случаи успешного лечения кольцевидной гранулемы апремиластом в течение 4 месяцев [53]. Отдельные работы посвящены применению метотрексата в дозе 12,515 мг в неделю. Положительный эффект наблюдался через месяц терапии, при этом около 64\% пациентов достигли полного или частичного регресса высыпаний [54]. Имеются отдельные публикации об эффрективности методов фототерапии при диссеминированной фрорме кольцевидной гранулемы [55-58]. В результате использования методов дальней длинноволновой ультрафиолетовой терапии, узкополосной (311нм) фототерапии, ПУВА-терапии отмечалась положительная динамика в виде частичного или полного регресса высыпаний.

Неясность этиологии и патогенеза заболевания определяет трудности в выборе терапии при различных формах заболевания. Нередко заболевание рефррактерно к проводимой терапии. По данным мировой литературы, до настоящего времени использование тех или иных системных лекарственных препаратов, а также методов фрототерапии ограничивается лишь описанием отдельных случаев. Это связано с редкостью дерматоза, недостаточностью опыта применения системных препаратов и методов фризиотерапевтического воздействия, а также отсутствием сравнительных рандомизированных исследований эффеективности различных видов терапии [59].

\section{Заключение}

В статье представлен успешный опыт комбинированного лечения с применением низких доз (1020 Дж/см²) дальней длинноволновой фототерапии в сочетании с низкоинтенсивным лазерным излучением инфракрасного спектра в лечении больных диссеминированной фрормой кольцевидной гранулемы. Полученные клинические результаты позволяют рекомендовать предложенную методику в клинической практике.

\section{Литература/References}

1. Харчилава М.Г., Хайрутдинов В.Р., Белоусова И.Э., Самцов А.В. Клинико-патоморфологические изменения кожи при кольцевидной гранулеме. Вестник дерматологии и венерологии. 2019; 95 (2): 8-14. [Kharchilava M.G., Khairutdinov V.R., Belousova I.E., Samtsov A. V. Clinical and pathological changes in the skin with granuloma annulare. Vestnik dermatologii i venerologii. 2019; 95 (2): 8-14 (Russia).]

2. Little E. G. Granuloma annulare. Proc R Soc Med. 1908; 1 (Dermatol Sect): $95-163$

3. Хебиф Т.Т. Кожные болезни: Диагностика и лечение. М. 2006; 574-577. [Habif Thomas P. Skin Disease. Diagnosis and Treatment. M., 2006; 574-577 (Russia).]

4. Кацамбас А.Д., Лотти Т.М. Европейское руководство по лечению дерматологических болезней. М., 2009; 230-233. [Katsambas A.D., Lotti T. M. European Handbook of Dermatological Treatments. M., 2009; 230—233 (Russia).]

5. Вольф К., Лоуэлл А. Голдсмит и др. Дерматология Фицпатрика в клинической практике. М., 2012; 401-405. [Wolff K., Lowell A. Goldsmith et al. Fitzpatrick's Dermatology in General Medicine. M., 2012; 401-405 (Russia).]

6. Vazquez-Lopez F., Gonzalez-Lopez M. A., Raya-Aguado C., Perez-OIiva N. Localized granuloma annulare and autoimmune thyroiditis: a new case report. J Am Acad Dermatol. 2000; 43 (5 Pt 2): 943_945.

7. Mangold A.R. et al. Clinical and histopathologic features of paraneoplastic granuloma annulare in association with solid organ malignancies: A case-control study. Journal of the American Academy of Dermatology. 2018; 79 (5): 913-920.

8. Ataş $\mathrm{H}$. et al. Two subsequent metachronous diseases: Granuloma annulare and colon adenocarcinoma. Journal of cancer research and therapeutics. 2018; 14 (2): 1247-1248.

9. Li A., Hogan D.J., Sanusi I.D., Smoller B.R. Granuloma annulare and malignant neoplasms. Am J Dermatopathol. 2003; 25: 113-116.

10. Cohen P.R. Granuloma annulare, relapsing polychondritis, sarcoidosis, and systemic lupus erythematosus: conditions whose dermatologic manifestations may occur as hematologic malignancy-associated mucocutaneous paraneoplastic syndromes. Int J Dermatol. 2006; 45: 70—80.
11. Shimizu S., Yasui C., Tsuchiya K. Atypical generalized granuloma annulare associated with two visceral cancers. J Am Acad Dermatol. 2006; 54 (5 Suppl): S. 236-238.

12. Setoyama M., Kerdel F.A., Byrnes J.J., Kanzaki T. Granuloma annulare associated with Hodgkin's disease. Int J Dermatol. 1997; 36: 445-448.

13. Schwartz R. A., Hansen R.C., Lynch P.J. Hodgkin's disease and granuloma annulare. Arch Dermatol. 1981; 117: 185-186.

14. Agrawal P. et al. Granuloma annulare: A rare dermatological manifestation of diabetes mellitus.Journal of family medicine and primary care. 2019; 8 (10): 3419.

15. Watanabe S., Tanaka M., Kobayashi K. et al. Remission of generalized erythematous granuloma annulare after improvement of hyperlipidemia and review of the Japanese literature. Dermatol Pract Concept. 2014; 4: $97-100$.

16. Wang Y.F., Yi G., Xu X.L. Generalized Interstitial Granuloma Annulare with Tuberculosis and Cutis Laxa: Case Report.International Journal of Dermatology and Venereology.2019; Publish Ahead of Print DOI: $10.1097 / J D 9.0000000000000060$.

17. Tambe S., Zambare U., Nayak C. Subcutaneous granuloma annulare in an HIV-positive patient International journal of STD \& AIDS. 2019; 30 (2): 206-208.

18. Ruocco E., Baroni A., Cutri F.T., Filioli F.G. Granuloma annulare in a site of healed herpes zoster: Wolf's isotopic response. J Eur Acad Dermatol Venereol. 2003; 17: 686-688.

19. Ma H.J., Zhu W.Y., Yue X.Z. Generalized granuloma annulare associated with chronic hepatitis B virus infection. J Eur Acad Dermatol Venereol. 2006; 20: 186-189.

20. Granel B., Serratrice J., Rey J. et al. Chronic hepatitis C virus infection associated with a generalized granuloma annulare. J Am Acad Dermatol. 2000; 43 (5 Pt 2): 918—919.

21. Chopra A. et al. Granuloma annulare skin lesions in a case of sarcoidosis.Indian dermatology online journal. 2018; 9 (2): 117.

22. Gradwell E., Evans S. Perforating granuloma annulare complicating tattoos. Br J Dermatol. 1998; 138: 360—361. 
23. Takayama K., Satoh T., Yokozeki H. Papular granuloma annulare with subcutaneous granulomatous reaction induced by a bee sting. Acta Derm Venereol. 2008; 88: 519—520.

24. Kakurai M., Kiyosawa T., Ohtsuki M., Nakagawa H. Multiple lesions of granuloma annulare following BCG vaccination: case report and review of the literature. Int J Dermatol. 2001; 40: 579—581.

25. Strahan J.E., Cohen J.L., Chorny J.A. Granuloma annulare as a complication of mesotherapy: a case report. Dermatol Surg. 2008 Jun; 34 (6): $836-838$.

26. Singh S. K., Manchanda K., Bhayana A.A., Verma A. Allopurinol induced granuloma annulare in a patient of lepromatous leprosy. J Pharmacol Pharmacother. 2013; 4: 152-154.

27. Cassone G., Tumiati B. Granuloma annulare as a possible new adverse effect of topiramate. Int J Dermatol. 2014; 53: 259—261.

28. Ahmad U., Li X., Sodeman T., Daboul I. Hepatitis C virus treatment with pegylated interferon-alfa therapy leading to generalized interstitial granuloma annulare and review of the literature. Am J Ther. 2013; 20: 585-587.

29. Li A., Hogan D. J., Sanusi I.D., Smoller B. R. Granuloma annulare and malignant neoplasms. Am. J. Dermatopathol. 2003; 25 (2): 113-6.

30. Chen A., Truong A.K., Worswick S. The role of biologics in the treatment of chronic granuloma annulare. International journal of dermatology. 2019; 58 (5): 622-626.

31. Chen A., Truong A.K., Worswick S. The role of biologics in the treatment of chronic granuloma annulare. International journal of dermatology. 2019; 58 (5): 622-626.

32. Fayyazi A., Schweyer S., Eichmeyer B., et al. Expression of IFN-gamma, coexpression of TNF-alpha and matrix metalloproteinases and apoptosis of T-lymphocytes and macrophages in granuloma annulare. Arch Dermatol Res. 2000; 292 (8): 384-390.

33. Pătraşcu V., Giurcă C., Ciurea R. N., Georgescu C.V. Disseminated granuloma annulare: study on eight cases. Rom. J. Morphol. Embryol. 2013; 54 (2): 327-31.

34. Dabski K., Winkelmann R.K. Generalized granuloma annulare: histopathology and immunopathology: systematic review of 100 cases and comparison with localized granuloma annulare. J. Am. Acad. Dermatol. 1989; 20 (1): 28-39.

35. Felner E. I., Steinberg J.B., Weinberg A. G. Subcutaneous granuloma annulare: a review of 47 cases. Pediatrics. 1997; 100 (6): 965-7.

36. Penas P.F., Jones-Caballero M., Fraga J., Sanchez-Perez J., Garcia-Diez A. Perforating granuloma annulare. Int. J. Dermatol. 1997; 36 (5): $340-8$.

37. Dabski K., Winkelmann R.K. Generalized granuloma annulare: histopathology and immunopathology: systematic review of 100 cases and comparison with localized granuloma annulare. J. Am. Acad. Dermatol. 1989; 20 (1): 28-39.

38. Piette E.W., Rosenbach M. Granuloma annulare: Clinical and histologic variants, epidemiology, and genetics. J Am Acad Dermatol. 2016 Sep; 75 (3): 457-465.

39. Kallioinen M., Sandberg M., Kinnunen T., Oikarinen A. Collagen synthesis in granuloma annulare. J Invest Dermatol. 1992 Apr; 98 (4): 463 - 468.

40. Huizenga T., Kado J.A., Pellicane B., Borovicka J., Mehregan D.R., Mehregan D.A. Interstitial granulomatous dermatitis and palisaded neutrophilic granulomatous dermatitis. Cutis. 2018 May; 101 (5): E19_E21.

41. Cohen P.R., Carlos C.A. Granuloma annulare mimicking sarcoidosis: report of patient with localized granuloma annulare whose skin lesions show 3 clinical morphologies and 2 histology patterns. The American Journal of Dermatopathology. 2015; 37 (7): 547-550.

42. Жилова М.Б., Волнухин В.А. Фототерапия псориаза: основные механизмы действия. Российский журнал кожных и венерических болезней. 2014; 6: 32-36. [Zhilova M. B., Volnukhin V.A. Phototherapy for psoriasis: Basic mechanisms of action. Russian journal of skin and veneral diseases. 2014; 6: 32—36 (Russia).]

43. York N.R., Jacobe H.T. UVA1 phototherapy: a review of mechanism and therapeutic application. International Journal of Dermatology 2010; 49: 623-630.

44. Gruss C., Reed J. A., Altmeyer P. et al. Induction of interstitial collagenase (MMP-1) by UVA-1 phototherapy in morphea. fibroblasts. Lancet. 1997; 350: 1295-6.

45. Petersen M. J., Hansen C., Craig S. Ultraviolet A irradiation stimulates collagenase production in cultured human fibroblasts. J Invest Dermatol. 1992; 99: 440-4.

46. Кочетков М.А., Волнухин В.А., Козлов В.И. Эффеективность применения низкоинтенсивного лазерного излучения В лечении больных кольцевидной гранулемой. Лазерная медицина. 2000; 4 (3): 1013. [Kochetkov M.A., Volnukhin V.A., Kozlov V.I. Low intensive laser radiation effectiveness in granuloma annulare treatment. Lasernaya Meditsina 2000; 4 (3): 10—13 (Russia).]

47. Bansal M., Pandey S. S., Manchanda K. Generalized papular granuloma annulare. Indian Dermatol Online J. 2012; 3 (1): 74-6.

48. Nambiar K.G. et al. Successful treatment of generalized granuIoma annulare with pentoxifylline.Indian dermatology online journal. 2017; 8 (3): 218

49. Chandan N. et al. Successful treatment of two individual cases of generalized granuloma annulare with amoxicillin/clavulanic acid and a combination of doxycycline and pentoxifylline.Dermatology online journal. 2018; 24 (8).

50. Weisenseel P. et al. Photodynamic therapy for granuloma annulare: more than a shot in the dark. Dermatology. 2008; 217 (4): 329_332.

51. Piaserico $S$. et al. Generalized granuloma annulare treated with methylaminolevulinate photodynamic therapy. Dermatology. 2009; 218 (3): 282-284.

52. Chen A., Truong A.K., Worswick S. The role of biologics in the treatment of chronic granuloma annulare. International journal of dermatology. 2019; 58 (5): 622-626.

53. Blum S., Altman D. Treatment of generalized granuloma annulare with apremilast: A report of 2 cases. JAAD case reports. 2019; 5 (11): 976.

54. Naka F., Strober B.E. Methotrexate treatment of generalized granuIoma annulare: a retrospective case series. Journal of Dermatological Treatment. 2018; 29 (7): 720-724.

55. Pavlovsky M. et al. NB-UVB phototherapy for generalized granuloma annulare. Dermatologic therapy. 2016; 29 (3): 152-154.

56. Aichelburg M. C. et al. Patch granuloma annulare: clinicopathological characteristics and response to phototherapy. British Journal of Dermatology. 2019; 181 (1): 198-199.

57. Attili S. K., Dawe R. S., Ibbotson S.H. Ultraviolet A1 phototherapy: One center's experience. Indian J Dermatol Venereol Leprol. 2017; 83 (1): $60-65$.

58. Schnopp C., Tzaneva S., Mempel M., Schulmeister K., Abeck D., Tanew A. UVA1 phototherapy for disseminated granuloma annulare. Photodermatol Photoimmunol Photomed. 2005; 21: 68-71.

59. Luk J., Schliemann S., Elsner P. Treatment of generalized granuloma annulare — a systematic review. JEADV. 2015; 29, 1467-1480. 


\section{Информация об авторах}

Карамова Арфеня Эдуардовна — к.м.н., заведующий отделом дерматологии ФГБУ «ГНЦДК» Минздрава России России

Знаменская Людмила Федоровна - д.м.Н., ведущий научный сотрудник отдела дерматологии ФГБУ «ГНЦДК» Минздрава

Свищенко Светлана Игоревна - к.м.н., заведующий отделением клинической дерматологии ФГБУ «ГНЦДК» Минздрава России

Жилова Марьяна Борисовна - д.м.н., заведующий физиотерапевтическим отделением ФГБУ «ГНЦДК» Минздрава России

Нефедова Мария Андреевна - младший научный сотрудник отдела дерматологии ФГБУ «ГНЦДК» Минздрава России

Пугнер Анна Степановна - врач-дерматовенеролог отделения клинической дерматологии ФГБУ «ГНЦДК» Минздрава России; e-mail: pugner@cnikvi.ru

\section{Information about the authors}

Arfenya E. Karamova - Cand. Sci. (Med)., Head of the Department of Dermatology, State Research Center of Dermatovenereology and Cosme-tology, Ministry of Health of the Russian Federation

Lyudmila F. Znamenskaya - Dr. Sci. (Med.), Leading Researcher, Department of Dermatology, State Research Center of Dermatovenereology and Cosmetology, Ministry of Health of the Russian Federation

Svetlana I. Svishchenko - Cand. Sci. (Med)., Head of the Department of clinical dermatology, State Research Center of Dermatovenereology and Cosmetology, Ministry of Health of the Russian Federation

Mar'yana B. Zhilova - Dr. Sci. (Med.), Head of the department of physical therapy State Research Center of Dermatovenereology and Cosmetology, Ministry of Health of the Russian Federation

Maria A. Nefedova - Junior Researcher, Dermatology Department, State Research Center of Dermatovenereology and Cosmetology, Ministry of Health of the Russian Federation

Anna S. Pugner - Dermatovenerologist, Department of clinical dermatology, State Research Center of Dermatovenereology and Cosmetology, Ministry of Health of the Russian Federation; e-mail: pugner@cnikvi.ru 